\title{
A procura do consumo financeiramente sustentável. Socialização e representações sociais do consumo, crédito e poupança
}

The Quest for Financially Sustainable Consumption. Socialization and Social

Representations of Consumption, Credit and Savings

La recherche de la consommation financièrement durable. Socialisation et

représentations sociales de la consommation, du crédit et de l'épargne

Raquel Barbosa Ribeiro, Susana Albuquerque, Jaime Raúl Seixas Fonseca, Carlos Bicho Pires e Diana Rodrigues Quintino

\section{OpenEdition}

Journals

Edição electrónica

URL: http://journals.openedition.org/rccs/5363

DOI: $10.4000 /$ rccs.5363

ISSN: 2182-7435

\section{Editora}

Centro de Estudos Sociais da Universidade de Coimbra

Edição impressa

Data de publição: 1 setembro 2013

Paginação: 65-88

ISSN: 0254-1106

Refêrencia eletrónica

Raquel Barbosa Ribeiro, Susana Albuquerque, Jaime Raúl Seixas Fonseca, Carlos Bicho Pires e Diana Rodrigues Quintino, «A procura do consumo financeiramente sustentável. Socialização e representações sociais do consumo, crédito e poupança», Revista Crítica de Ciências Sociais [Online] 101 | 2013, posto online no dia 17 fevereiro 2014, consultado o 04 fevereiro 2021. URL: http:// journals.openedition.org/rccs/5363 ; DOl: https://doi.org/10.4000/rccs.5363

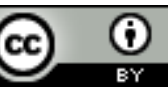




\section{RAQUEL BARBOSA RIBEIRO, SUSANA ALBUQUERQUE, JAIME RAÚL SEIXAS FONSECA, CARLOS BICHO PIRES, DIANA RODRIGUES QUINTINO}

\section{A procura do consumo financeiramente sustentável. Socialização e representações sociais do consumo, crédito e poupança}

Este artigo apresenta uma perspetiva sociológica sobre o consumo, o crédito e a poupança em Portugal. Partindo da problemática sobre as potencialidades e limitações da educação para o consumo, centramo-nos na importância da socialização. Como são formadas as representações do consumo financeiramente sustentável pelos consumidores? O objetivo é analisar qual a valorização que estes atribuem às mensagens e fontes de informação sobre dinheiro, consumo, crédito, dívida e poupança. Avalia-se no presente artigo a importância relativa atribuída à família, aos amigos, à escola, aos média e às organizações na disseminação e credibilização destas mensagens. Para o efeito, apresentam-se os resultados de quatro projetos de pesquisa com crianças, jovens e adultos, realizados entre 2009 e 2012.

Palavras-chave: comportamento do consumidor; consumo; crédito ao consumidor; poupança; socialização.

\section{Introdução}

Este artigo enquadra-se num conjunto de reflexões sobre as práticas de consumo, frequentemente tidas como preocupantes nas sociedades ocidentais contemporâneas (Comissão Europeia, 2007). A assunção, embora nem sempre fundamentada, de que a gestão de muitos orçamentos particulares se pauta por níveis disfuncionais de gasto, dívida e incumprimento financeiro, com consequências complexas e amplas para as sociedades e os Estados (Lopes e Frade, 2012; Santos, 2013), tem levado à procura de explicações e soluções, num debate multidisciplinar longe de estar encerrado. ${ }^{1}$

\footnotetext{
${ }^{1}$ Santos (2013) faz notar que, ainda que a dívida das famílias portuguesas tenha crescido a um ritmo acelerado nas últimas duas décadas, atingindo $95 \%$ do PIB em 2010, apenas $40 \%$ das famílias participava no mercado da dívida e a taxa de crédito mal parado das famílias em geral não ultrapassava os 3\%. Lopes e Frade (2012) sustentam que Portugal tem uma das taxas mais baixas de incumprimento financeiro da Europa dos 27, quando comparado com países com taxas de endividamento semelhantes, mas alertam para o risco iminente de agravamento do incumprimento nos próximos anos em resultado da atual crise económica.
} 
Este impõe-se com especial premência pelo crescimento de iniciativas de educação para o consumo, de literacia financeira e de inovações sociais, que têm como objetivo fomentar o equilíbrio financeiro dos particulares (veja-se, por simples exemplo, o Plano Nacional da Formação Financeira e as suas atividades com escolas e professores).

O nosso contributo será eminentemente sociológico. Sendo já conhecidas estatísticas (Banco de Portugal, 2010) e pesquisas económicas e psicológicas sobre estas temáticas (Santos, Costa e Teles, 2013; Oliveira e Jesus, 2013), importa considerar os mecanismos sociais que enquadram as decisões de consumo, particularmente as decisões financeiras que implicam a escolha entre gasto, poupança e crédito. De um leque amplo de possibilidades de investigação, este artigo foca-se na importância da socialização para a formação das escolhas de consumo, propondo a seguinte questão: como são formadas as representações do consumo financeiramente sustentável pelos consumidores? O objetivo principal é analisar a valorização das mensagens e das fontes de informação sobre dinheiro, consumo, crédito, dívida e poupança pelos consumidores. Neste âmbito, avalia-se a importância relativa da família, dos amigos, da escola, dos média e das organizações na disseminação e credibilização destas mensagens.

Referem-se, em primeiro lugar, algumas explicações sociológicas para as decisões de consumo, oriundas de diferentes paradigmas teóricos. Presta-se atenção à esgrima conceptual entre consumo sustentável, consumo responsável e literacia financeira. Segue-se um resumo de contributos teórico-empíricos sobre a socialização e as representações do consumo por diferentes agentes. São apresentados os resultados de quatro estudos desenvolvidos em Portugal sobre esta matéria e, por fim, a sua discussão e uma síntese conclusiva.

\section{O consumo numa perspetiva sociológica}

Para a sociologia, a tentativa de explicar o consumo pode implicar o estudo da satisfação de necessidades ou desejos, da comunicação de distinções sociais, do reforço de padrões de superioridade e inferioridade entre indivíduos e grupos, da simbolização de sucesso ou poder, da expressão de estados de espírito ou de formas de comunicação interpessoal (Campbell, 1995; Cruz, 2013). Para alguns autores, a escolha de consumo é resultante de uma decisão ponderada, racional e livre; para outros, impera o poder do subconsciente ou da dominação social. Consome-se por sentido prático ou por razões simbólicas, culturais e comunicacionais (Ribeiro, 2011). A forma como as escolhas de consumo são construídas em contexto social é entendida de modo diferente consoante a perspetiva teórica. 
Uma das perspetivas enfatiza o papel da estrutura social na determinação das escolhas de consumo, tratando-o como um fenómeno acionado a partir de necessidades que são geradas e satisfeitas num contexto de interdependência entre vários agentes - família, amigos, grupos de referência, estrato social, sistema educativo ou profissional, entre outros -, extravasando a mera função utilitária. Nesta corrente estão patentes preocupações de cariz estruturalista, ocupando-se da "mecânica" social que leva a que os indivíduos submetam, consciente ou inconscientemente, as suas ações aos ditames sociais, através dos mecanismos de reprodução social (Bourdieu, 1979) e sobre os significados e atribuições simbólicos das escolhas de consumo e a construção da identidade (Slater, 2005). Esta análise do consumo associa-se estreitamente à discussão sociológica sobre a hierarquização social, especialmente a classe.

Menos consensual mas defendida, ainda que sob forte polémica, por alguns teóricos da sociologia económica, a teoria da ação racional aplicada ao consumo assume-o como resultado de uma escolha de cariz essencialmente racional por parte do indivíduo que, previamente munido de informação disponível sobre as diferentes opções, prefere a mais vantajosa (Voss e Abraham, 2000). Esta teoria também considera a obtenção de gratificações emocionais ou sociais, advenientes do altruísmo, da cooperação ou da adesão às normas, como formas de utilidade (Beckert, 1996). Porém, os comportamentos sociais dependentes de preferências instáveis, variáveis ou fracas, como o comportamento do consumidor, são pobremente explicados por estas análises (Friedman e Hechter, 1988). Os sociólogos criticam o "reducionismo económico" e o "reducionismo psicológico" (Lie, 1997). Granovetter (1985) celebrizou a questão que designou por "the problem of embeddedness", ao realçar o papel das redes sociais, da amizade e do parentesco na construção de uma boa vontade geral que sustenta as relações e instituições económicas.

O pós-modernismo trata o consumo como um instrumento de afirmação individual, reabilitando o "direito" à escolha individual como o fizeram os teóricos da ação racional, mas sob uma ótica relativista e não puramente utilitária; Featherstone (1991) descreveu a ideia de que passaria a ser o estilo de vida (lifestyle) a definir as identidades pessoais e sociais dos indivíduos, assumindo que determinados comportamentos, manifestamente de consumo, iriam permitir a cada pessoa construir o seu próprio eu e a sua imagem. O estilo de vida é "a individualidade do gosto", cujos indicadores mais comuns seriam os consumos categorizados por hábitos de lazer, passatempos e gosto no que toca a vestuário, música e livros ou o tipo de férias, entre outros (Katz-Gerro e Shavit, 1998). Esta convicção de que 
o consumo seria libertador e criativo também mereceu críticas, por exemplo as de quem entende que o consumo é mais um ato prático do que cultural (Lodziak, 2000), de quem defende que a influência dos outros nas escolhas de consumo é mais forte do que a autoexpressão individual (Lichtenberg, 1996) ou de quem recorda que as condições financeiras continuam a ser imprescindíveis para a "livre" criação de estilos de vida (Bogenhold, 2001).

A teoria da prática aplicada ao consumo (veja-se o estado da arte em Warde, 2005 e Halkier et al., 2011) propõe uma alternativa ao individualismo e ao condicionamento social extremados. Tem inerente a ideia de que grande parte dos comportamentos deriva do hábito, da rotina, do conhecimento tácito ou da tradição e não necessariamente do livre arbítrio consciente nem de julgamentos ou classificações sociais, mesmo tendo patente a importância da socialização e do babitus de Bourdieu. Halkier et al. realçam a utilização da teoria da prática na investigação sobre a sustentabilidade e a mudança comportamental (2011: 5). Dwyer (2009) invoca o hábito como possível explicação para o crescimento dos níveis de consumo, aflorando a questão da dívida como resultado de uma habituação a certos padrões de vida. Porém, a gestão financeira não foi mais desenvolvida pela teoria da prática.

Refletindo sobre a literatura produzida acerca deste tema (Ribeiro, 2011), encontramos três alicerces: primeiro, não existe consumo que não seja influenciado pelo social. A sociedade modela qualquer ação humana e os comportamentos de consumo são aprendidos e praticados socialmente. Segundo, embora relativizando a presunção do pós-modernismo de que a autodefinição de identidades é livre, os teóricos do consumo orientam-se cada vez mais para aceitar que o indivíduo desempenha um papel considerável no processo de consumo. Terceiro, é difícil destrinçar os momentos em que os comportamentos dos consumidores são tendencialmente racionais ou emocionais. A racionalidade em sentido estrito é, como vimos, limitada na explicação das decisões de consumo, que são socialmente condicionadas por mecanismos complexos que geram as suas próprias normas.

Mormente as suas divergências internas, este quadro teórico tem o mérito de nos projetar para questões interessantes como a formulação de expectativas orientadoras da tomada de decisão de consumo, as influências sociais nas decisões sobre o gasto, a dívida, a poupança e o investimento ou o conflito entre o prazer, a moral, os valores e os hábitos na aquisição de bens e serviços. Ressalve-se, contudo, que a sociologia do consumo tem sido prolífica na identificação das razões para gastar, mas não quanto às razões para poupar e investir. Impõe-se, por isso, a sugestão de uma agenda de pesquisa alargada sobre estas temáticas. 


\section{Consumo sustentável, consumo responsável e literacia financeira}

A crítica ao gasto, à ostentação e à alienação é recorrente na sociologia desde os anos 50 (Ribeiro, 2011); só mais recentemente o consumo sustentável começou a merecer-lhe também uma abordagem regular. Ainda assim, a pesquisa tem incidido mais nos aspetos ecológicos e sociocomunitários do consumo responsável, do que na literacia financeira, no crédito, na dívida e na poupança (áreas nas quais a economia e a psicologia têm sido mais participativas).

A controvérsia sobre os conceitos de necessidade - que consumos são "necessários" ou "supérfluos" e em que circunstâncias - e de racionalidade - com o antagonismo entre livre-arbítrio, consciência e calculismo, por um lado e manipulação, impulso e emotividade, por outro - tem acendido vários debates, nos quais a carga moral e política dos argumentos utilizados torna por vezes difícil destrinçar a análise da filosofia (ibidem). As opiniões de sociólogos (e não só) dividem-se frequentemente entre as que defendem que o consumo é mau, enquanto símbolo da queda da humanidade de um anterior "estado de graça", do desvio da autossuficiência ideal, do exacerbamento do controlo e da competição social, da agudização das desigualdades, do desperdício e da contaminação dos recursos naturais, e as que se inclinam para a presunção de que o consumo é bom, necessário e desejável para o crescimento da economia, fonte de prazer e fator de desenvolvimento da estética, das artes e da criatividade (Miller, 1995; Zukin e Maguire, 2004). Esta segunda visão tem sido comparativamente menos desenvolvida pela sociologia, em especial no que respeita à questão do prazer, do gozo e da fruição. Têm predominado antes as considerações de que o prazer não é verdadeiramente individual mas sim uma coação social; de que o prazer não é duradouro e está condenado a perecer na mó da insaciabilidade; de que o prazer desaparece na sensação de vazio que o consumo não colmatou; ou de que o prazer está moralmente errado, porque é pueril, egoísta, gastador ou irresponsável (Warde, 2005; Ribeiro, 2011).

Assim, duas imagens do consumidor têm dominado a literatura sobre o consumo nas ciências sociais: a primeira, central na teoria económica, é a de que o consumidor toma parte ativa, calculista e racional, alguém que aloca recursos escassos na compra de bens e serviços de forma a obter a máxima utilidade; a outra, frequentemente encontrada nos críticos do "consumo de massas", é a de que o consumidor é um sujeito passivo, manipulado, enganado e explorado pelo capitalismo (Lie, 1997), patente na Escola de Frankfurt e em Baudrillard (1968), por exemplo, que alegavam que o capitalismo precisa de produzir necessidades para a sociedade de consumo continuar a funcionar. Uma terceira forma de encarar o consumidor, emergente 
com o pós-modernismo, teria passado a representá-lo como um manipulador consciente dos significados simbólicos associados aos produtos. Campbell (2005) sugere, ainda, uma nova e quarta imagem, assente no pressuposto de que os indivíduos respondem ativamente aos bens e serviços e os usam conscientemente como meios para atingir os seus fins materiais, psicológicos e sociais; o autor faz menção ao papel do artesanato e do "faça-você-mesmo", que, por oposição aos produtos produzidos industrialmente de forma massificada, podem ser sinónimos de libertação, criatividade e bom gosto.

Este entendimento inscreve-se no debate em torno dos direitos e deveres dos consumidores (Henry, 2010), encontrando-se as questões da sustentabilidade em ambas as aceções. A sustentabilidade interliga-se com os domínios da ecologia, do desenvolvimento sustentável, da responsabilidade social, do comércio justo, das inovações sociais e das comunidades autofinanciadas, entre outros. Para Miles (2011), o consumo sustentável faz-se através da combinação de uma "ética de consumo" (que visa reduzir os níveis de consumo) com o "consumo ético" (que advoga opções de consumo menos nocivas para o ambiente).

Neto e Coelho (2011) utilizam a expressão "consumo responsável” para designar uma manifestação de cidadania que implica a redução dos níveis de consumo, a reutilização, o restauro, a reciclagem e a utilização de formas de produção e recursos mais saudáveis e socialmente justos. Foà et al. (2012) analisam as motivações que inspiram escolhas de consumo responsável, evidenciando o desejo dos consumidores de promover a igualdade e as relações humanas através de formas económicas alternativas, o desejo de satisfação pessoal através do consumo de produtos de qualidade e o desejo de protegerem o ambiente e de se protegerem a si próprios. Os quatro eixos à volta dos quais se articulam os principais significados que movem os consumidores responsáveis são o bem-estar, a crítica, a sobriedade e a solidariedade. Os autores referem a classificação de Di Nallo et al. (2006), que traçam o perfil do consumidor ético. O consumidor responsável sobrepõe a dimensão coletiva ao plano meramente individual da satisfação pessoal. O consumidor consciente está atento ao impacto das suas ações e do mercado, acreditando que a segurança, a proteção ambiental e o respeito dos direitos do ser humano representam direitos fulcrais. O consumidor sustentável, através das suas escolhas de consumo, procura melhorar a qualidade da sua vida e a dos outros, concentrando-se numa visão unitária dos aspetos ecológicos, económicos e sociais, e procurando garantir um futuro melhor para as próximas gerações. O consumidor crítico pratica ações de boicote e contrainformação, escolhe produtos locais e artesanais, com circuitos curtos de distribuição ou provenientes de formas de troca que não implicam o dinheiro. 
Embora a questão ambiental tenha vindo a ser central no entendimento do consumo sustentável, pode também identificar-se a noção de consumo financeiramente sustentável (Cohen, 2007) que pressupõe a tentativa de manter gastos controlados e um endividamento sustentável; ou seja, "a capacidade de contrair crédito sem comprometer a possibilidade de o reembolsar quando tal seja devido" (Frade e Jesus, 2011: 77). Acredita-se que o consumo financeiramente sustentável é suportado pela literacia financeira e pela competência (capability) financeira. A literacia financeira é determinada pela informação sobre rendimentos, gasto, crédito, poupança e investimento e pela mudança comportamental daí adveniente (Johnson e Sherraden, 2007). A competência financeira é definida como o conjunto de conhecimentos necessários, a capacidade e a oportunidade de agir para tomar decisões financeiras apropriadas, gerindo recursos financeiros, monitorizando o estado das próprias finanças, fazendo um planeamento para o futuro e procurando informação atualizada sobre temas económicos (Stumm et al., 2013). O Banco de Portugal (2010) condensa ambos os conceitos na definição que adota para literacia financeira: a capacidade de fazer julgamentos informados e tomar decisões concretas tendo em vista a gestão do dinheiro, incluindo a gestão do orçamento familiar, o controlo da conta bancária e a escolha de produtos e serviços bancários adequados às necessidades dos consumidores; Jorgensen e Savla (2010) definem-na sucintamente como a relação entre conhecimento financeiro, atitudes financeiras e comportamentos financeiros. A Comissão das Comunidades Europeias (2007) refere que a educação financeira - que é o meio para construir a competência, segundo McCormick (2009) - capacita os indivíduos para uma melhor compreensão dos produtos e conceitos financeiros.

Contudo, grande parte da população continua pouco informada para fazer escolhas financeiras ou avaliar produtos financeiros complexos e, até à data, há muito pouca evidência rigorosa sobre o impacto da educação financeira (Hamilton et al., 2012); o enfoque tem sido mais nos resultados finais (as alterações no comportamento) do que nos mecanismos de impacto, que constituem elementos de avaliação importantes, pelo que têm sido defendidos mecanismos de avaliação da causalidade entre educação financeira e literacia financeira (Carpena et al., 2011).

\section{Socialização e representações do consumo}

A socialização é o processo segundo o qual os indivíduos aprendem a agir e interagir em sociedade e a socialização para o consumo é o processo de aquisição e desenvolvimento de valores, atitudes, normas, conhecimentos e comportamentos sobre a escolha e utilização de bens e serviços (veja-se 
Jorgensen e Savla, 2010 e Ribeiro, 2011). A investigação em ciências sociais tem demonstrado a relação que existe entre a socialização para o consumo das crianças e a sua ulterior aplicação na idade adulta (Anderson e Nevitte, 2006; Cook, 2008; Ruckenstein, 2010). A afetação de recursos financeiros depende não só do rendimento disponível, do património e da conjuntura económica, mas também da estrutura moral, da educação recebida, da criação de hábitos ou do modo de encarar a gratificação do consumo. Alguns tópicos de interesse incluem a transmissão intergeracional de atitudes e comportamentos parentais; o efeito das estratégias de marketing e publicidade nas crianças, com as suas implicações legais e éticas; a influência, a negociação e a manipulação dos pais e educadores pelas crianças e as políticas sociais e de defesa do consumidor (John, 1999). As teorias do consumo têm ainda mencionado o tema do consumo a propósito da mediação na relação entre pais e crianças, da aprendizagem do e para o consumo, da reprodução social, das dinâmicas da mudança social e das ansiedades parentais sobre o consumo (Martens et al., 2004).

Na socialização para o consumo, podemos identificar o papel de agentes diversos, como a família, os amigos, a escola, os média e as organizações com e sem fins lucrativos.

Sendo os pais a influência chave na vida das crianças, as atitudes e conhecimentos que os adultos desenvolvem no futuro em relação ao dinheiro e ao consumo são influenciados primariamente por eles. Acredita-se que o ensino das matérias ligadas ao consumo e às finanças deve caber às famílias, muito embora estas amiúde não tenham a preparação necessária para o efeito (Jorgensen e Savla, 2010). Uma das formas mais importantes de socialização em questões de consumo é através da mesada ou semanada dada pelos pais aos filhos; regista-se uma relação entre experiências de infância quanto ao uso do dinheiro e a capacidade ulterior para a gestão do mesmo (Furnham e Argyle, 1998; Ruckenstein, 2010). Assim, os pais funcionam como selecionadores e controladores das noções adquiridas sobre o consumo, através dos seus ensinamentos e do modo como cultivam as "formas de consumir" corretas (Martens et al., 2004). As crianças aprendem em casa, com a assistência dos média, em especial da TV, os principais elementos do "consumo-orientado-para objetivos"; aprendem também com os seus pares o elemento expressivo do consumo e aprendem na escola algo sobre as funções adaptativas do consumo; porém, cada vez menos aprendem como poupar e mais sobre como gastar (Riesman, 1993). A poupança é, não obstante, generalizadamente aprovada e recompensada socialmente, consubstanciando um projeto moral de educação (Ruckenstein, 2010). 
As redes sociais (família e amigos) são a principal fonte de informação sobre poupança e investimento (Chang, 2005). Cerca de $41 \%$ dos agregados familiares estudados recorriam a familiares e amigos, $27 \%$ ao funcionário bancário, $21 \%$ aos média (especialmente a imprensa) e $21 \%$ ao seu consultor financeiro. Aproximadamente $15 \%$ declararam não consultar ninguém. Enquanto os mais ricos pagavam a profissionais e recorriam a média especializados, os menos abonados confiavam mais nos conselhos de familiares e amigos, assim como nos média. As razões para recorrer ao círculo de indivíduos próximos eram a isenção de custos, a facilidade e a confiança. Embora a rede social dos mais pobres pudesse ser menor, o seu uso era mais frequente. No que respeita ao crédito, estudos indicam que a quantidade de informação dada pelos pais aos filhos é significativamente maior do que a proporcionada por outras fontes, como os pares, a escola e os média, existindo uma relação diretamente proporcional entre a informação que os pais dão aos filhos sobre o crédito e o uso financeiramente sustentável que os filhos fazem do cartão de crédito (Pinto et al., 2005). As outras fontes de informação não mostraram estar relacionadas com o uso do cartão de crédito.

O entendimento da conduta competente de consumo varia com os grupos sociais e comporta diferentes interpretações de valores e gostos culturais (Martens et al., 2004). Os recursos simbólicos da cultura de consumo global oferecem uma versão do "outro generalizado", mas a interação com os outros significantes revela a mediação que estes exercem, pelas suas crenças e práticas, em diferentes regimes regulatórios (Langer, 2005). Nas sociedades ocidentais, é cultivada a ideologia da autonomia na gestão do dinheiro e do consumo e o elogio da poupança. O consumo também está implicado nas representações da idade adulta, muito embora abundem as contradições entre a "racionalidade" que se ensina às crianças e a "irracionalidade" que caracteriza muitos comportamentos adultos, das quais as crianças se apercebem (Ruckenstein, 2010). Durante o crescimento dos jovens, assiste-se ao aumento das influências para além dos pais, nomeadamente por parte dos grupos de pares, podendo gerar-se confusão e ansiedade (Martens et al., 2004). Os adolescentes podem mesmo receber reforço positivo em relação a escolhas financeiras incorretas por parte dos seus pares (Sherraden et al., 2011).

A socialização para o consumo é ainda fortemente determinada pelo babitus das classes sociais (Bourdieu, 1979). Furnham e Argyle (1998) notaram que as crianças da classe média, mesmo recebendo uma mesada menor do que as da classe operária, poupavam mais; por outro lado, os indivíduos de estratos socioeconómicos mais baixos explicam a pobreza 
sobretudo com razões de cariz social, enquanto os de estratos socioeconómicos mais elevados avançam explicações mais individualistas (como falta de parcimónia e de gestão adequada do dinheiro). A autorresponsabilização e a visão a longo prazo é mais associada às classes média e alta, ao passo que a poupança (por necessidade de prover às despesas do quotidiano e não numa ótica de investimento) é mais atribuída às classes baixas (Ribeiro, 2011). Os níveis de literacia financeira são mais baixos na população com menores rendimentos e menos instrução (Lusardi e Mitchell, 2008) e os programas de educação financeira parecem ser eficazes apenas nos públicos de estrato socioeconómico elevado.

A socialização para o consumo exercida pelas organizações pode revestir-se de finalidades lucrativas e não lucrativas. No primeiro caso, encontramos as estratégias de marketing e publicidade orientadas pela motivação da compra. Têm aumentado os estudos sobre a importância da aprendizagem informal sobre o consumo, através dos média, da internet e do lazer, que complementam os estudos de socialização levados a cabo pela escola e pela família (Larsson et al., 2010). As representações mediáticas sobre o consumo incidem na falta de autocontrolo, no uso do cartão de crédito e em estereótipos como o viciado em compras e a mulher que gasta de mais (Starr, 2007). Os conteúdos mediáticos não são apenas transmitidos - são selecionados, modificados, apropriados e aplicados pelos consumidores, obrigando a estudar o modo como as mensagens são recebidas, interpretadas e representadas. A influência dos média e da publicidade aumenta com a idade dos jovens, por causa do fortalecimento dos laços sociais e da necessidade de aceitação à medida que a adolescência avança (Martens et al., 2004). No segundo caso, as preocupações prendem-se essencialmente com a recomendação de um freio aos gastos e a aplicação proveitosa dos recursos, transmitindo uma visão positiva da poupança e negativa do gasto e do crédito (Starr, 2007). Em resposta à atual crise financeira e económica, as organizações têm dedicado vastos recursos a programas de educação financeira, que têm como principais objetivos a promoção de escolhas de consumo que previnam o sobreendividamento e o incumprimento financeiro, capacitando a população para a gestão orçamental, a poupança e o investimento - em linha com os princípios do marketing social, que é a gestão estratégica do processo de transformação social para a adoção de novos comportamentos, atitudes e práticas orientados por princípios éticos (Foà et al., 2012). Valores como a solidariedade, a poupança $\mathrm{e}$ a ecologia são difundidos pelos média (Ribeiro e Lourenço, 2013), porém, o papel destes é particularmente ambivalente, porquanto veiculam simultaneamente conteúdos publicitários de encorajamento ao gasto e conteúdos editoriais de moralização do consumo (Starr, 2007). 
Em Portugal e no resto da União Europeia, a educação para o consumo e para a poupança deveriam ser abordadas nos programas escolares, conforme determinado pelas recomendações comunitárias, mas tal ainda não aconteceu. É notável o aumento dos programas de educação para o consumo; porém, em Portugal, estas iniciativas são quase todas privadas (promovidas por instituições financeiras, organizações de defesa do consumidor e fundações; veja-se Ribeiro e Quintino, 2013). Jackson (2005) nota, no entanto, que as campanhas de informação pública parecem ter menos sucesso do que outros tipos de aprendizagem informal quotidiana, fazendo lembrar os princípios da teoria da prática. $\mathrm{O}$ autor defende uma abordagem mais proativa e criativa, que leve em conta as circunstâncias estruturais que podem levar ao consumo excessivo. Ribeiro e Lourenço (2013) notam também que a comunicação para a responsabilidade que utilize estímulos positivos, no conteúdo e na forma, poderá ter maior capacidade para chamar a atenção do público-alvo e encorajar a utilização do que é preconizado.

Muito tem sido dito sobre os conteúdos educativos que "devem" ser ensinados aos consumidores (Starr, 2007), embora pouco se debata, ainda, sobre o conhecimento e a legitimidade de quem produz tais recomendações. A nosso ver, importa também compreender quem socializa para o consumo e que conteúdos e emissores são efetivamente apreendidos e valorizados, levando em conta que, para além do equilíbrio financeiro próprio e do seu agregado, os consumidores tendem a procurar satisfazer padrões de aceitação, prestígio e conformidade social, a reproduzir práticas enraizadas nos seus hábitos e, em alguns casos, a adaptar estratégias recomendadas de forma criativa ao seu próprio estilo de vida (conforme as teorias sociológicas sobre o consumo atrás referidas).

\section{Metodologia}

Para estudar a importância da socialização para as decisões de consumo que implicam a escolha entre gasto, poupança e crédito, definiu-se como pergunta de partida: como são formadas as representações de consumo financeiramente sustentável pelos consumidores? A partir dos contributos de Cohen (2007) e Frade e Jesus (2011), apresentados na secção 2, definimos o consumo financeiramente sustentável como a tentativa de manter gastos controlados, garantir a poupança e evitar o incumprimento financeiro. Em nosso entender, o consumo financeiramente sustentável, se considerado na ótica dos consumidores e não apenas como uma definição científica, é produto das suas representações sociais, em resultado do seu contexto social. Estas representações advêm da socialização para o consumo em sentido lato e da apropriação que dela é feita pelos indivíduos, sendo o 
produto complexo de normas, valores, crenças, atitudes, representações e práticas, num processo eminentemente moral de reprodução e transmissão cultural (Ruckenstein, 2010). Queremos assim abarcar na pesquisa não só a ideia de consumo responsável (na aceção de Neto e Coelho, 2011) e de consumo financeiramente competente e ético (Di Nallo et al., 2006; Johnson e Sherraden, 2007; Stumm et al., 2013), mas também a de consumo moralmente recomendado, de forma implícita ou explícita, pelos agentes de socialização. Por este motivo, consideramos importante realçar o papel da socialização para o consumo e não apenas da educação financeira.

O objetivo principal deste artigo é analisar a valorização das mensagens e das fontes de informação sobre dinheiro, consumo, crédito, dívida e poupança pelos consumidores. Pretende-se especificamente avaliar a importância dos agentes de socialização, como a família, os amigos, a escola, os média e as organizações, na disseminação e credibilização das mensagens sobre o consumo financeiramente sustentável.

Para o efeito, analisam-se os resultados de quatro estudos desenvolvidos em Portugal, entre 2009 e 2012, com o intuito de identificar comportamentos e representações de consumo, dinheiro e poupança, averiguar as fontes de informação e aprendizagem dos consumidores e conhecer a sua opinião sobre os conteúdos mediáticos, comerciais e pedagógicos relativos a questões financeiras. A revisão da literatura permitiu perceber que a transmissão intergeracional, as redes sociais, o efeito das estratégias de marketing e publicidade e os conteúdos mediáticos são elementos relevantes a ter em conta no estudo da socialização para o consumo. Por conseguinte, procurámos contemplar, para além da generalidade da população portuguesa, três populações específicas: crianças, por serem um alvo sensível de comunicação e por haver necessidade de mais estudos sobre a sua aprendizagem, perceção e prática do consumo, que se revestem de características próprias; jovens universitários, por estarem na transição da adolescência para a idade adulta, recebendo estímulos ao consumo que se intensificam nesta fase da vida (Martens et al., 2004), particularmente de instituições bancárias que, em parceria com vários estabelecimentos de ensino, procuram conquistá-los como consumidores; e consumidores de produtos bancários, por serem decisores financeiros ativos em operações com alguma complexidade.

O primeiro estudo, de 2009, visou a identificação e caracterização dos comportamentos de consumo e poupança da população portuguesa e assentou num questionário online com perguntas abertas e fechadas, com a participação de 550 entrevistados, dos 12 aos 70 anos de idade, residentes em todos os distritos de Portugal. O questionário foi colocado à disposição num sítio da internet vocacionado para a pesquisa quantitativa, entre 20 de abril 
e 6 de julho de 2009. A divulgação do questionário foi efetuada recorrendo a uma amostra teórica junto de instituições públicas e privadas, procurando garantir-se a diversidade amostral no que toca à distribuição por sexos, idades, região, nível de instrução e profissão. A amostra foi composta por $59 \%$ de mulheres e $41 \%$ de homens. $17 \%$ dos respondentes tinham entre 12 e 24 anos, $46 \%$ entre 25 e 34 anos e $37 \%$ entre 35 e 70 anos. Os inquiridos da Grande Lisboa representaram 39\% do total; 20\% pertenciam ao Grande Porto e Litoral Norte; $12 \%$ viviam no Interior Norte; $10 \%$ viviam no Litoral Centro; 14\% habitavam no Alentejo e Algarve e cerca de 3\% nas Regiões Autónomas.

O segundo estudo, de 2011, pretendeu investigar as representações e práticas financeiras das crianças, através de pesquisa qualiquantitativa junto de 245 crianças do $3 .^{\circ}$ e do $4 .^{\circ}$ ano de escolaridade, dos 8 aos 12 anos de idade, bem como dos seus encarregados de educação e professores. Estas crianças encontravam-se a frequentar a Escola Básica Arquiteto Victor Palla na Penha de França, que cobre uma população de um estrato socioeconómico médio-baixo e a Escola dos Salesianos, no Estoril, que abarca um estrato socioeconómico médio-alto e alto. Na pesquisa utilizaram-se reuniões de grupo, entrevistas individuais e inquéritos por questionário, em articulação com as Direções das escolas. O trabalho de campo decorreu entre fevereiro e março de 2011. As atividades foram desenvolvidas com o consentimento dos encarregados de educação. Colaboraram na pesquisa António Gabriel, professor de Ensino Especial da Escola Básica Arquiteto Victor Palla e Sara Lopes Martins, estudante de Sociologia no ISCSP-UTL.

O terceiro estudo, de 2012, teve como objetivo conhecer os hábitos de procura de informação sobre dinheiro, poupança e crédito dos jovens universitários. Enquanto estudo exploratório, abarcou apenas a região de Lisboa. A amostra englobou 705 estudantes das faculdades FLUL, FCT, ESTB, IST, FCSH, ISCSP, ISEG, FCUL, ISPA e ISCTE², a quem foram aplicados questionários autoadministrados. A recolha de dados decorreu em novembro de $2012.57 \%$ dos respondentes eram do sexo feminino e $43 \%$ do sexo masculino. As idades estavam compreendidas entre os $17 \mathrm{e}$ os 32 anos, com a mediana nos 19 anos.

\footnotetext{
${ }^{2}$ FLUL: Faculdade de Letras da Universidade de Lisboa; FCT: Faculdade de Ciências e Tecnologia da Universidade Nova de Lisboa; ESTB: Escola Superior de Tecnologia do Barreiro; IST: Instituto Superior Técnico da Universidade Técnica de Lisboa; FCSH: Faculdade de Ciências Sociais e Humanas da Universidade Nova de Lisboa; ISCSP: Instituto Superior de Ciências Sociais e Políticas da Universidade Técnica de Lisboa; ISEG: Instituto Superior de Economia e Gestão da Universidade Técnica de Lisboa; FCUL: Faculdade de Ciências da Universidade de Lisboa; ISPA: Instituto Superior de Psicologia Aplicada; ISCTE: Instituto Superior de Ciências do Trabalho e da Empresa.
} 
O quarto estudo, de 2012, teve como intuito caracterizar os comportamentos dos consumidores de produtos bancários portugueses, recorrendo a um questionário online aplicado a 193 indivíduos acima dos 18 anos, com instrução ao nível do ensino secundário ou superior, através de uma amostra teórica recrutada através de divulgação em instituições de ensino e empresas. Pediu-se aos participantes que, entre outras informações, relatassem a busca de informação sobre produtos e serviços bancários nos últimos cinco anos. A pesquisa decorreu entre setembro e novembro de 2012. A população inquirida abrangeu os distritos de Lisboa (47\%), Porto, Braga e Viana do Castelo (10\%), Aveiro e Coimbra (7\%), Faro, Beja, Évora, Portalegre e Setúbal (36\%). 65\% dos inquiridos eram do sexo feminino e $35 \%$ do sexo masculino.

\section{Socialização e representações sociais do consumo, crédito e poupança: resultados}

Os resultados do primeiro estudo, de 2009, cujo objetivo foi caracterizar os comportamentos e representações de consumo e poupança da população portuguesa, mostram que a aprendizagem do consumo, do dinheiro e da poupança foi atribuída, na grande maioria dos casos (86\%), à educação recebida dos pais; porém, apenas 59\% dos inquiridos disseram falar amiúde sobre estas questões no seu círculo de familiares e amigos (com uma percentagem de $77 \%$ nas idades entre os 18 e os 24 anos). Alargando a procura de informação aos média, $50 \%$ dos inquiridos pensaram que seria fácil encontrar informação sobre estes assuntos e 36\% entenderam que os média explicavam as melhores formas de gerir o dinheiro. Cerca de 19\% dos respondentes atribuíram à escola o papel de ensinar sobre consumo, dinheiro e poupança. Embora 27\% dos inquiridos com mais de 45 anos acreditassem que se aprendem estas matérias na escola, só $14 \%$ dos respondentes com menos de 18 anos concordaram. Apenas 18\% dos inquiridos com 24 anos ou mais e instrução superior declarou ter conhecimento deste ensino na escola, subindo esta percentagem para $36 \%$ na população da mesma idade sem instrução superior.

$81 \%$ dos inquiridos defenderam que, quando se consegue poupar, é-se mais dono da própria vida e $75 \%$ afirmaram que a poupança deve ser motivo de orgulho; $44 \%$ entenderam que poupar deve ser mesmo uma obrigação moral de qualquer pessoa. Os dados qualitativos obtidos a partir das perguntas abertas mostram que a representação da poupança englobou duas dimensões: tempo (futuro) e dificuldade, fosse pelo esforço de contenção, planeamento e aforro que a poupança exige e pelos custos de oportunidade derivados da opção de não gastar, fosse pela utilização prevista do montante 
amealhado (à qual poderia estar subjacente uma associação a percalços ou períodos menos favoráveis da vida, como a doença ou o desemprego). A poupança foi também associada a privação, doença, velhice e estratos socioeconómicos desfavorecidos.

$90 \%$ das mulheres disseram que os pais as ensinaram a poupar, contra $80 \%$ dos homens. $72 \%$ não garantiram que os seus amigos tivessem hábitos de poupança. Apenas $27 \%$ dos inquiridos disseram estar a par da oferta dos bancos e seguradoras em matéria de poupança e investimento. $54 \%$ afirmaram confiar inteiramente em si para encontrar as melhores formas de poupar e investir. Cerca de $23 \%$ costumavam aconselhar-se com familiares e amigos a respeito destas temáticas e 19\% sentiam que precisavam de ter mais informação sobre as melhores formas de poupar.

No segundo estudo, de 2011, sobre as representações e práticas financeiras das crianças, a maioria das crianças inquiridas disse acreditar que não se consegue viver sem dinheiro (77\%) e que quem poupa vive melhor do que quem não poupa (74\%). 97\% das crianças evocaram que a sua família dizia que poupar era importante; $79 \%$ atribuíram aos pais a mensagem de que o dinheiro não é para desperdiçar e $72 \%$ a de que não se deve gastar o dinheiro. No entanto, só $64 \%$ das crianças declararam que os pais falavam habitualmente com elas sobre dinheiro (já 80\% dos pais disseram fazê-lo).

A necessidade de estudar para arranjar um bom emprego foi uma recomendação recebida dos pais por $87 \%$ das crianças. O dever de ajudar os outros, alegadamente ensinado pelos pais, foi referido por $76 \%$ das crianças (de notar que apenas 36\% dos pais disse recomendar aos filhos que deveriam ajudar os outros). Cerca de $9 \%$ terão ouvido dos pais que podia comprar o que quisesse e que o dinheiro servia para a diversão. Falar de dinheiro com os amigos só pareceu ser comum para 30\% destas crianças.

Dinheiro e poupança também são temas recorrentes nos anúncios para $65 \%$ dos alunos da Penha de França e 80\% dos Salesianos. Das perceções sobre os conteúdos mediáticos (filmes, anúncios e desenhos animados) em ambas as escolas, ressaltaram as mensagens de que os ricos são mais felizes $(69 \%)$, de que quem trabalha muito é recompensado (64\%), de que com dinheiro se consegue o que se quer $(51 \%)$ e de que os pais dão tudo aos filhos $(41 \%)$.

O terceiro estudo, de 2012, com o intuito de conhecer os hábitos de procura de informação sobre dinheiro, poupança e crédito dos jovens universitários em Lisboa, revelou que a informação recebida pelos inquiridos, diária ou semanalmente, sobre dinheiro, poupança e crédito vinha principalmente dos familiares $(71 \%)$, de notícias nos média $(54 \%)$, da publicidade $(50 \%)$ e dos amigos $(48 \%)$. Foram consideradas muito credíveis pelos estudantes 
as informações recebidas dos familiares (58\%), dos organismos privados de informação ao consumidor, como a Deco (43\%), dos organismos públicos com a mesma vocação, como Instituto do Consumidor, Banco de Portugal, União Europeia, Instituto de Seguros de Portugal, CMVM, etc. (41\%) e dos amigos (37\%). Foram considerados pouco credíveis os conteúdos da publicidade $(52 \%)$, das empresas privadas $(38 \%)$, dos bancos e seguradoras $(32 \%)$ e dos artigos e blogues na internet (32\%). Sobre os artigos nos média, $52 \%$ consideraram-nos razoavelmente credíveis e $26 \%$ pouco credíveis. Relativamente aos conteúdos das mensagens recebidas, diária ou semanalmente, destacou-se a recomendação de aproveitar descontos ou promoções $(61 \%)$, preferir compras mais baratas $(60 \%)$ e gastar menos em bens ou serviços não essenciais (55\%). O encorajamento ao investimento foi uma mensagem comparativamente menos notada pelos respondentes $(21 \%)$. Para estes estudantes universitários, a noção de poupança estava associada a gastar menos em bens ou serviços não essenciais (37\%), gastar menos ou não gastar de um modo geral ( $23 \%)$, e criar uma reserva ou um fundo de dinheiro (21\%).

Cerca de $49 \%$ considerou insuficiente a informação que é dada às crianças e adolescentes sobre estes temas. Segundo os inquiridos, o principal educador sobre este assunto tem sido a escola (33\%); sendo apontados em seguida os organismos públicos de informação ao consumidor (15\%) e outras entidades de formação (14\%). O papel dos familiares pareceu ser muito reduzido; embora $71 \%$ dos universitários dissessem receber da família a maior parte da informação sobre consumo, dinheiro e crédito, apenas $3 \%$ acreditavam que os pais têm sido os principais informadores das crianças e adolescentes sobre estas matérias. Quando questionados sobre quem não deveria informar as crianças e adolescentes sobre poupança, $23 \%$ referiram a publicidade e $20 \%$ as empresas privadas.

O quarto estudo, de 2012, pretendeu caracterizar os comportamentos dos consumidores de produtos bancários portugueses. Para os inquiridos, as maiores preocupações no último ano, enquanto clientes bancários, foram a constituição ou aumento de poupanças $(35 \%)$ e a redução das despesas com cartões de crédito $(28 \%)$. A busca de aconselhamento profissional para a tomada de decisões financeiras foi algo que $94 \%$ dos respondentes ao inquérito não colocaram como hipótese. $42 \%$ procuraram, no último ano, informações sobre produtos e serviços financeiros, sobretudo sobre taxas de juro de depósitos a prazo $(33 \%)$ e condições de subscrição de produtos de poupança $(33 \%)$. Na busca de informações sobre produtos e serviços bancários, os participantes na investigação referiram que preferiam obter informações através da internet $(28 \%)$ ou diretamente no balcão do 
seu banco $(27 \%)$. Apenas $13 \%$ dos respondentes afirmaram entrar em contacto com uma pessoa de confiança no seu banco e só $11 \%$ falaram com familiares e amigos para o efeito; os média não foram consultados por mais de $8 \%$. Sobre a oferta percebida dos bancos, $48 \%$ referiram o aumento de produtos de poupança nos últimos cinco anos e $37 \%$ notaram o crescimento da comunicação bancária através de revistas, emails e newsletters. Muito embora $88 \%$ digam confiar pouco ou nada no sistema financeiro português, $83 \%$ confiam no seu banco principal.

\section{Discussão e síntese conclusiva}

Os resultados apontam para crenças já indiciadas em outros estudos (Martens et al., 2004; Anderson e Nevitte, 2006; Jorgensen e Savla, 2010) de que a educação financeira é exercida, principalmente, pela família e que esta constitui o agente socializador que merece maior credibilidade, quando comparado com os média, os amigos ou vários tipos de organizações. Jorgensen e Savla (ibidem) salientam, porém, que embora os consumidores acreditem que o ensino das matérias ligadas ao consumo e às finanças deve caber às famílias, estas nem sempre têm a preparação necessária para responder a todas as necessidades de informação financeira.

Os conteúdos transmitidos pelos pais aos filhos sobre consumo parecem colocar uma grande ênfase na poupança, confirmando a ideia de Ruckenstein (2010: 388) de que a poupança faz parte de um projeto moral, aprovada e recompensada socialmente. A ideia de poupança encerra representações de dificuldade, contenção e planeamento para as várias populações em estudo, ao passo que a sua dimensão de investimento parece menos presente. O nosso estudo indica que, em termos de normatividade social percebida, o destaque dado à poupança, em diversos períodos (incluindo o anterior aos primeiros indicadores de recessão económica), se manteve muito elevado, em diferentes gerações. Este poderá ser um elemento de reflexão importante na análise de dados e controvérsias sobre a gravidade do endividamento em Portugal (Santos, 2013).

O papel dos pais merece algumas reflexões adicionais sobre as diferenças entre intenções e práticas: há um desfasamento entre a opinião de pais e filhos quanto às conversas habituais em família acerca de dinheiro, sendo que os universitários acreditam que os pais são pouco informadores das crianças e dos adolescentes sobre estas matérias. Também a transmissão de valores de solidariedade e de ajuda financeira dos pais às crianças parece ser mais idealizada por estas do que concretizada pelos próprios pais. As dificuldades e ansiedades dos pais na educação para o consumo foram referidas por John (1999) e Martens et al. (2004), tendo Ruckenstein (2010) notado 
a importância do dinheiro como instrumento relacional e de solidariedade para as crianças, bem como a incongruência entre os comportamentos dos adultos e aquilo que estes ensinam às crianças. Nos conteúdos mediáticos, as crianças deste estudo sublinharam as mensagens de riqueza associada à felicidade e ao poder, da recompensa financeira do trabalho árduo. A indulgência parental foi notada pelas crianças ao evocar os anúncios publicitários, mas tanto elas como os seus pais afirmam que não é transmitida em casa, de pais para filhos.

Embora o menor peso dos amigos, quando comparados com os familiares, nos interlocutores das conversas financeiras das crianças e dos jovens possa revelar a falta de conhecimentos sobre estas matérias (já que a influência dos pares pode aumentar o erro nas decisões financeiras, segundo Sherraden et al., 2011), também poderá dever-se a desinteresse ou à crença de que tais assuntos devem ser discutidos apenas no seio da família. A confirmar-se, este pode ser um obstáculo à socialização completa para o consumo financeiramente sustentável, na medida em que os modelos dos grupos de pares ganham um peso crescente com a idade (Martens et al., 2004).

Os média aparentam constituir uma fonte importante de informação, após a família e os amigos. Os nossos resultados são semelhantes aos que Chang (2005) encontrou nos agregados familiares de menores rendimentos, que valorizavam mais a informação oriunda da família e dos média. No entanto, a credibilidade dos média para os nossos investigados não é muito elevada. Como ressalva Starr (2007), nos conteúdos mediáticos convivem apelos publicitários ao consumo e artigos críticos do consumo, o que pode gerar confusão e desconfiança nos públicos. Os consumidores de produtos bancários notaram um aumento da comunicação das instituições financeiras nos últimos anos e mostraram desconfiança no sistema financeiro português (mas não no seu banco); para os universitários, as mensagens oriundas da publicidade e do setor privado com fins lucrativos, especialmente bancos e seguradoras, foram consideradas pouco credíveis, pelo que as crianças e adolescentes não deveriam ser informadas por estes agentes. Este é, assim, um setor de atividade cuja informação desperta vários sentimentos negativos e mesmo os seus programas de educação para o consumo, sob a égide do marketing social, permanecem envoltos em polémica (Ribeiro e Quintino, 2013; Santos, 2013).

Sobre a escola, nota-se a opinião de que pouco é feito por esta instituição em termos de educação para o consumo, sendo as expectativas sobre o seu papel também pouco elevadas. Parece haver um contraste que merece ser assinalado entre o estudo de 2009 , no qual a convicção de que a escola não estava a desempenhar a função de educadora financeira era bastante vincada 
entre os mais jovens e os indivíduos com instrução superior, e o estudo de 2012, no qual os universitários apontam a escola como principal educador de facto das crianças e adolescentes (mas não deles próprios) sobre este tema, mesmo se com um protagonismo partilhado com os organismos públicos de informação ao consumidor e outras entidades de formação. É possível que exista a perceção da orientação recente da escola para a educação financeira, à qual poderá não ser alheio o crescimento de programas ad hoc de literacia financeira nas escolas, muito embora a educação financeira no seio destas ainda não tenha sido implementada formalmente conforme recomendações da OCDE (Ribeiro e Quintino, 2013).

O processo de socialização para o consumo, apesar de assumir particular importância na infância, perdura ao longo do ciclo de vida, influenciando atitudes, valores, hábitos e comportamentos. A importância das redes sociais neste processo e o cunho moral de muitas mensagens transmitidas sugerem que os mecanismos de reprodução social invocados pela teoria sociológica permanecem relevantes. Porém, a procura de informação diversificada, o julgamento da qualidade e veracidade das mensagens recebidas e a preocupação com alvos mais sensíveis mostram que o consumidor não parece ser tão passivo nem manipulado como temiam os autores da teoria crítica. Apesar de as potencialidades do consumidor-produtor referido por Campbell (2005), que crescentemente prefere tomar a iniciativa do que delegar em instituições, as limitações da socialização para o consumo pelos vários agentes sociais e a perceção do baixo envolvimento da escola sugerem a necessidade de melhorar a educação formal sobre estas temáticas para aumentar os conhecimentos financeiros na população. Isto pressupõe a remoção de barreiras institucionais encontradas pelos indivíduos, nomeadamente de rendimentos mais baixos (Johnson e Sherraden, 2007) e o conhecimento das necessidades e recursos concretos dos destinatários (Anderson et al., 2004).

A poupança, no sentido do freio ao gasto, parece estar bastante associada a dificuldade, pobreza e dever, enquanto o planeamento e o investimento são conotados com classes médias e altas, denotando estas convicções a persistência da reprodução social e do hábito. A representação da poupança como estratégia de contenção, mais do que de investimento, embora possa ser reflexo da estrutura socioeconómica portuguesa (Ribeiro, 2011) pode limitar o espectro e o tom da socialização para o consumo. A acreditar na importância das mensagens positivas para a sustentabilidade (Ribeiro e Lourenço, 2013) e na convicção dos inquiridos de que a poupança capacita e deve ser motivo de orgulho, a sua representação como trampolim de aspirações pode ser vantajosa nas estratégias comunicacionais pedagógicas, 
especialmente junto dos mais novos. A poupança como refúgio de estabilidade no fim da vida, ou como plano de contingência para dias cinzentos, que se afigura remota e negativa, pode dar lugar a uma representação mais ambiciosa, que compreenda várias motivações e possa adaptar-se a diferentes momentos da vida.

Espera-se que a consolidação teórico-empírica das pesquisas, nomeadamente no âmbito da teoria da prática, possa trazer novos contributos ao estudo do consumo, bem como potenciar uma maior colaboração interdisciplinar sobre a temática. Ressalva-se ainda que a questão do consumo financeiramente sustentável remete para debates de cariz moral e ético, sobre os quais importará continuar a refletir.

\section{Referências bibliográficas}

Anderson, C. Leigh; Nevitte, Neil (2006), "Teach your Children Well: Values of Thrift and Saving", Journal of Economic Psychology, 27(2), 247-261.

Anderson, C. Leigh; Zahn, M.; Scott, J. (2004), "Targeting Financial Management Training at Low-income Audiences", The Journal of Consumer Affairs, 38(1), 167-177.

Banco de Portugal (2010), Relatório do inquérito à literacia financeira da população portuguesa. Lisboa: Banco de Portugal.

Baudrillard, Jean (1968), A sociedade de consumo. Lisboa: Edições 70.

Beckert, Jens (1996), "What is Sociological about Economic Sociology? Uncertainty and the Embeddedness of Economic Action", Theory and Society, 25(6), 803-840.

Bogenhold, Dieter (2001), "Social Inequality and the Sociology of Life Style: Material and Cultural Aspects of Social Stratification (Focus on Economic Sociology)", The American Journal of Economics and Sociology, 60(4), 829-847.

Bourdieu, Pierre (1979), La distinction - critique sociale du jugement. Paris: Editions de Minuit.

Campbell, Colin (1995), "The Sociology of Consumption", in Daniel Miller (org.), Acknowledging Consumption. London: Routledge, 96-126.

Campbell, Colin (2005), "The Craft Consumer", Journal of Consumer Culture, 5, 23-42. Carpena, Fenella; Cole, Shawn; Shapiro, Jeremy; Zia, Bilal (2011), "Unpacking the Casual Chain of Financial Literacy", World Bank Development Research Group, Finance and Private Sector Development Team. Consultado a 20.12.2012, em http://www-wds. worldbank.org/servlet/WDSContentServer/WDSP/IB/2011/09/19/000158349_20 110919154530/Rendered/PDF/WPS5798.pdf.

Chang, Mariko Lin (2005), "With a Little Help from my Friend (and my Financial Planner)”, Social Forces, 83(4), 1469-1497.

Cohen, Maurie J. (2007), "Consumer Credit, Household Financial Management, and Sustainable Consumption”, International Journal of Consumer Studies, 31(1), 57-65. 
Comissão Europeia (2007), "EU Consumer Policy Strategy 2007-2013. Empowering Consumers, Enhancing their Welfare, Effectively Protecting Them". Communication from the commission to the council, the European Parliament, and the European Economic and Social Committee COM (2007), 99.

Comissão das Comunidades Europeias (2007), "Comunicação da Comissão: Educação Financeira”. COM (2007) 808 final. Consultado a 20.12.2012, em http://eur-lex. europa.eu/LexUriServ/LexUriServ.do?uri=COM:2007:0808:FIN:PT:PDF.

Cook, Daniel Thomas (2008), "The Missing Child in Consumption Theory", Journal of Consumer Culture, 8, 219-243.

Cruz, Isabel Silva (2013), Entre estruturas e agentes: padrões e práticas de consumo em Portugal Continental. Porto: Afrontamento.

Di Nallo, Egeria; Paltrinieri, Roberta; Arvidsson, Adam (2006), Cum Sumo: Prospettive di Analisi del Consumo nella Società Globale. Milano: Franco Angeli.

Dwyer, Rachel (2009), "Making a Habit of It: Positional Consumption, Conventional Action and the Standard of Living", Journal of Consumer Culture, 9(3), 328-347.

Featherstone, Mike (1991), Consumer Culture and Postmodernism. London: Sage.

Foà, Caterina; Alves, Sofia Branquinho; Pereira, João Santos (2012), "Consciencializar para os aspectos sociais do Marketing”, in Raquel Barbosa Ribeiro (org.), Marketing para estudantes de Comunicação. Lisboa: Causa das Regras, 269-290 [2. 'edição].

Frade, Catarina; Jesus, Fernanda (2011), "Percepção do risco de crédito e endividamento sustentável”, in Hernâni Veloso Neto e Sandra Lima Coelho (orgs.), Novas dimensões do consumo na sociedade contemporânea. Porto: IS-FLUP, 69-82.

Friedman, Debra; Hechter, Michael (1988), “The Contribution of Rational Choice Theory to Macrosociological Research", Sociological Theory, 6(2), 201-218.

Furnham, Adrian; Argyle, Michael (1998), A psicologia do dinheiro. Lisboa: Sinais de Fogo.

Granovetter, Mark (1985), "Economic Action and Social Structure: the Problem of Embeddedness", The American Journal of Sociology, 91(3), 481-510.

Halkier, Bente; Katz-Gerro, Tally; Martens, Lydia (2011), “Applying Practice Theory to the Study of Consumption: Theoretical and Methodological Considerations", Journal of Consumer Culture, 11(1), 3-13.

Hamilton, Leah; Shobe, Marcia; Murphy-Erby, Yvette; Christy, Kameri (2012), "It's All About Security to Me. The Role of Environment in Youth Financial Literacy and Savings Behaviors", SAGE Open, 2(4), 1-8.

Henry, Paul C. (2010), "How Mainstream Consumers Think about Consumer Rights and Responsibilities", Journal of Consumer Research, 37(4), 670-687.

Jackson, Tim (2005), Motivating Sustainable Consumption: A Review of Evidence on Consumer Behaviour and Behavioural Change. University of Surrey: Centre for Environmental Strategy.

John, Deborah Roedder (1999), "Consumer Socialization of Children: A Retrospective Look at Twenty-five Years of Research”, Journal of Consumer Research, 26(3), 183-213. 
Johnson, Elizabeth; Sherraden, Margaret S. (2007), "From Financial Literacy to Financial Capability among Youth”, Journal of Sociology \& Social Welfare, 34(3), 119-146.

Jorgensen, Bryce. L.; Savla, Jyoti (2010), "Financial Literacy of Young Adults: The Importance of Parental Socialization”, Family Relations, 59(4), 465-478.

Katz-Gerro, Tally; Shavit, Yossi (1998), "The Stratification of Leisure and Taste: Classes and Lifestyle in Israel”, European Sociological Review, 14(4), 369-386.

Langer, Beryl (2005), "Research Note: Consuming Anomie: Children and Global Commercial Culture”, Childhood, 12(2), 259-271.

Larsson, Bengt; Andersson, Magnus; Osbeck, Christina (2010), “Bringing Environmentalism Home Children's Influence on Family Consumption in the Nordic Countries and Beyond", Childhood, 17(1), 129-147.

Lichtenberg, Judith (1996), “Consuming Because Others Consume”, Social Theory and Practice, 22(3), 273-298.

Lie, John (1997), "Sociology of Markets”, Annual Review of Sociology, 23, 341-360.

Lodziak, Conrad (2000), “On Explaining Consumption”, Capital \& Class, 72, 111-133.

Lopes, C. Abreu; Frade, Catarina (2012), “The Way into Bankruptcy: Market Anomie and Sacrifice among Portuguese Consumers", Journal of Consumer Policy, 35, 477-496.

Lusardi, Annamaria; Mitchell, Olivia S. (2008), "Planning and Financial Literacy: How do Women Fare?”, American Economic Review: Papers and Proceedings, 98(2), 413-417.

Martens, Lydia; Southerton, Dale; Scott, Sue (2004), "Bringing Children (and Parents) into the Sociology of Consumption Towards a Theoretical and Empirical Agenda”, Journal of Consumer Culture, 4(2), 155-182.

McCormick, Martha Henn (2009), "The Effectiveness of Youth Financial Education: A Review of the Literature", Journal of Financial Counseling and Planning, 20(1), 70-83.

Miles, Steven (2011), "Why Sustainability Doesn't Matter (to Consumers)", in Hernâni Veloso Neto e Sandra Lima Coelho (orgs.), Novas dimensões do consumo na sociedade contemporânea. Porto: IS-FLUP, 30-37.

Miller, Daniel (org.) (1995), Acknowledging Consumption. London: Routledge.

Neto, Hernâni Veloso; Coelho, Sandra Lima (2011), "Consumo responsável: uma tentativa de problematização de um fenómeno social contemporâneo”, in Hernâni Veloso Neto e Sandra Lima Coelho (orgs.), Novas dimensões do consumo na sociedade contemporânea. Porto: IS-FLUP, 8-28.

Oliveira, Miguel; Jesus, Fernanda (2013), “Arquitetura situacional do crédito: tempo, cognição, afeto e decisão”, Revista Crítica de Ciências Sociais, 101, 39-64.

Pinto, Mary Beth; Parente, Diane H.; Mansfield, Phylis M. (2005), "Information Learned from Socialization Agents: Its Relationship to Credit Card Use”, Family and Consumer Sciences Research Journal, 33(4), 357-367.

Ribeiro, Raquel Barbosa (2011), Consumo e classes sociais em Portugal: auto-retratos. Lisboa: Causa das Regras. 
Ribeiro, Raquel Barbosa; Lourenço, Joana (2013), “A comunicação para a responsabilidade. Análise de campanhas de responsabilidade financeira, ambiental e social dirigidas às crianças", in Hernâni Veloso Neto e Sandra Lima Coelho (orgs.), Proceedings Cive Morum 2013 International Congress. Vila do Conde: Civeri Publishing, 13-17. Ribeiro, Raquel Barbosa; Quintino, Diana (2013), “A educação para o consumo em Portugal: uma análise crítica de programas públicos e privados”, in Hernâni Veloso Neto e Sandra Lima Coelho (orgs.), Proceedings Cive Morum 2013 International Congress. Vila do Conde: Civeri Publishing, 147-150.

Riesman, David (1993), Abundance for What. New Jersey: Transaction Publishers [1. ${ }^{a}$ ed.: 1964, Doubleday \& Company].

Ruckenstein, Minna (2010), “Time Scales of Consumption: Children, Money and Transaccional Orders", Journal of Consumer Culture, 10, 383-403.

Santos, Ana Cordeiro (2013), “Temos vivido acima das nossas possibilidades?”, in José Soeiro; Miguel Cardina; Nuno Serra (orgs.), Não acredite em tudo o que pensa. Lisboa: Edições Tinta-da-China.

Santos, Ana Cordeiro; Costa, Vânia; Teles, Nuno (2013), “A economia política do consumo e do crédito: um contributo interdisciplinar", Revista Crítica de Ciências Sociais, 101, 9-38.

Sherraden, Margaret Sherrard; Johnson, Lissa; Guo, Baorong; Elliott III, William (2011), "Financial Capability in Children: Effects of Participation in a School-based Financial Education and Savings Program", Journal of Family and Economic Issues, 32(3), 385-399.

Slater, Don (2005), "The Sociology of Consumption and Lifestyle”, in Craig Calhoun; Chris Rojek; Bryan S. Turner (orgs.), The SAGE Handbook of Sociology. London: Sage, 174-187.

Starr, Martha. A. (2007), "Saving, Spending, and Self-control: Cognition versus Consumer Culture”, Review of Radical Political Economics, 39, 214-229.

Stumm, Sophie von; Fenton O'Creevy, Mark; Furnham, Adrian (2013), "Financial Capability, Money Attitudes and Socioeconomic Status: Risks for Experiencing Adverse Financial Events", Personality and Individual Differences, 54, 344-349.

Voss, Thomas; Abraham, Martin (2000), "Rational Choice Theory in Sociology: A Survey”, in Stella R. Quah e Arnaud Sales (orgs.), The International Handbook of Sociology. London: Sage, 50-83.

Warde, Alan (2005), "Consumption and Theories of Practice", Journal of Consumer Culture, 5(2), 131-153.

Zukin, Sharon; Maguire, Jennifer Smith (2004), “Consumers and Consumption”, Annual Review of Sociology, 30, 173-197. 
